\title{
PRONTO KIDS CHAPECÓ: digital prototyping and fabrication workshops focused on the perception of the built environment for children in the public school system
}

XXIV International Conference

of the Iberoamerican Society

of Digital Graphics

Medellin | Colombia

\author{
Luana Peroza Piaia \\ Unochapecó | Brasil | luanapiaia@unochapeco.edu.br \\ Carla Cristina Secchi \\ Unochapecó | Brasil | cah_secchi@unochapeco.edu.br \\ Ana Carolina Hemsing \\ Unochapecó | Brasil | anahemsing@unochapeco.edu.br \\ Paola Avila \\ Unochapecó | Brasil | paola.avila@unochapeco.edu.br
}

\begin{abstract}
The inclusion of digital fabrication and prototyping in the school environment contributes significantly to learning, stimulating the cognitive process of students. The objective is to introduce concepts of these technologies to students from municipal public schools, relating to the built environment. The action research procedure is developed through practical workshops in a university's laboratory. The workshops promoted clarification about digital technologies for children, encouraging them to reflect on elements that promote improvement in the built environment. The approach with technologies since the beginning of citizen education, points to societies aware of the transformations in the environment in which they live.
\end{abstract}

Keywords: Digital Fabrication; Digital Prototyping; Teaching; Child Learning.

\section{INTRODUÇÃO}

Diariamente, o ambiente construído é vivenciado e sentido por indivíduos de todas as idades. Este espaço, constituído por residências, praças, indústrias e equipamentos, contribui na formação intelectual do ser humano e na sua percepção sobre o ambiente vivido. Por meio da Arquitetura e do Urbanismo é possível sentir e explorar o local o qual se está inserido, em referência à composição visual da paisagem que se observa. Partindo desta perspectiva, podem atuar de forma interdisciplinar em conteúdos das mais diversas áreas, como história, ciência, física, química, artes, matemática, entre outras. Portanto, inseri-los desde o início da trajetória escolar, como uma forma de ensino, tende a contribuir no modo com que se percebe 0 ambiente, colaborando na formação de cidadãos comprometidos com o bem-estar social (Angelo, Neves, \& Campos, 2012).

A organização não governamental UIA (International Union of Architects), consultora da UNESCO (Organização das Nações Unidas para a Educação, a Ciência e a Cultura), possui como um de seus programas o Architecture and Children (Arquitetura e Crianças), o qual expõe aos jovens as práticas de uma boa arquitetura, voltada ao pensamento de um ambiente construído sustentável, no qual os cidadãos são protagonistas responsáveis e conscientes (Angelo et al., 2012). O programa acredita que, a qualidade e o futuro do ambiente construído estão nas mãos das crianças, e, sendo elas agentes transformadores da sociedade, a forma como lhes é repassado o conhecimento influencia nas suas capacidades, habilidades e decisões futuras (Angelo et al.,
2012). Para Angelo et al. (2012), ainda se insere neste contexto a cidade como promotora da conscientização sustentável de seus habitantes, como parte das políticas públicas municipais de planejamento socioeconômico e ambiental.

De acordo com Papert (1999), Piaget é considerado o primeiro pesquisador a dar importância ao pensamento das crianças, propondo uma reforma educacional centrada em nova metodologia de aprendizado infantil, após longos anos de pesquisas e estudos. Piaget é responsável por grande contribuição nas áreas da Psicologia e Pedagogia com pesquisas voltadas para a análise e observação científica do processo de aprendizagem do ser humano (Papert, 1999). Como síntese, o autor descreve que o homem pode desenvolver sua própria compreensão do mundo (Silva, 2019).

Para Raabe, Metzger, Jesus, Jesus Filho e Cucco (2018), o Construcionismo discutido por Papert é associado à uma forma de aprendizagem por meio do fazer, pois acredita que aprender é ainda mais importante do que ensinar. Entende-se que a teoria do Construcionismo, trazida pelo estudioso, se configura como uma vertente do Construtivismo de Piaget, que tem como principal conceito a aprendizagem através da construção do conhecimento (Raabe et al., 2018). Nesta perspectiva, a criança constrói seu pensamento a partir do fazer, tendo o computador como uma ferramenta essencial (Pinto, Azevedo, Teixeira, Brasil, \& Hamad, 2018) 
Conforme salienta Raabe et al. (2018), o movimento maker se apoia na teoria do Construcionismo de Papert. Este é caracterizado por impulsionar a produção e materialização de projetos colocando a 'mão na massa', ou seja, baseiase na cultura DIY (Do It Yourself), que incentiva a criação e manufatura de objetos por indivíduos sem familiaridade na área (Raabe et al., 2018). Trazendo os preceitos do movimento maker para a sala de aula, o estudante passa a ser defendido como o protagonista da criação dos projetos, refletindo uma abordagem impactante na organização educacional. Pinto et al. (2018) também defende que grande parte das atividades makers tem como base metodológica a abordagem Construcionista de Papert, impulsionando o indivíduo a atuar como o protagonista na prática a ser realizada.

$\mathrm{O}$ ato de fazer algo com as próprias mãos, ou como a expressão 'botar a mão na massa', segundo Angelo et al. (2012), faz com que o indivíduo interaja diretamente com o ambiente, agregando valor ao objeto pensado, criado e materializado. Trazer o lúdico para o ensino de crianças tem produzido efeitos positivos, despertando maior interesse pelas atividades que estão sendo propostas, aguçando suas percepções sensoriais, estimulando a memória e melhorando assim suas habilidades (Brancher, Chenet, \& Oliveira, 2011).

Com a evidente influência do ambiente construído sobre seus usuários, mesmo sendo quem o cria e transforma, pressupõe-se que, repassar o conhecimento para crianças e jovens, conectando temas como arquitetura, sustentabilidade, inovação e tecnologia, os tornará indivíduos conscientes de seus atos sobre a paisagem na qual vivem. No âmbito das possibilidades de inserção destes assuntos no ensino, visando uma forma dinâmica, prática e simples, destacam-se as tecnologias digitais.

Estas ferramentas têm alterado o cenário mundial, fomentadas pela Quarta Revolução Industrial ou Indústria 4.0. Com a inserção tecnológica, há a possibilidade de mudança na forma de ensinar e estimular o processo criativo e cognitivo dos estudantes (Pupo \& Celani, 2008). De acordo com Pupo e Celani (2008), tecnologias denominadas prototipagem e fabricação digitais, desempenham um papel decisivo no método de ensino atual, pois oportunizam possibilidades projetuais que anteriormente não eram alcançadas.

O advento global da disseminação das ferramentas de fabricação e prototipagem digitais foi possibilitado, em 2003, por meio da criação do Fab Lab (fabrication laboratory) MIT (Massachusetts Institute of Technology), do Center for Bit and Atoms, da mesma instituição (Ballerini, 2018). Atualmente, a rede engloba mais de 100 países e 1.750 Fab Labs em todo o mundo, tendo no Brasil mais de 30 laboratórios credenciados (Fab Lab, 2020). É importante ressaltar que, muitos laboratórios de fabricação e prototipagem digitais não são vinculados à rede internacional, portanto, estima-se que este número possa ser muito maior.

Os equipamentos presentes nestes laboratórios, em sua maioria, são impressoras 3D, cortadoras a laser e maquinários CNC (Computer Numerically Controlled Controle Numérico Computadorizado) Router, que possibilitam o processo de materialização da forma, por meio da produção de protótipos nas mais diferentes escalas (Pupo, 2009). A tecnologia BIM (Building Information Modeling) e as ferramentas CAD (Computer
Aided Design), estimulam o aceleramento do processo de projeto e permitem precisa compatibilização de informações entre os envolvidos.

A fabricação e prototipagem digitais são ferramentas de apoio ao processo de projeto, permitindo a concretização de vários objetos que vão desde maquetes físicas a peças finais de uma construção (Pupo, 2009). Para Pupo (2009), o uso destas técnicas em maquetes e protótipos possibilita melhor comunicação e entendimento do projeto, que talvez não fosse possível ser evidenciado somente com a representação digital.

A inserção de tecnologias digitais no ambiente escolar contribui significativamente no processo de aprendizagem, estimulando as crianças na busca por mudanças para o local onde vivem (Vilaça \& Araújo, 2016). Para isso, é imprescindível a observação do contexto social em que estão inseridas, pois será no dia a dia que exercerão o papel de agentes transformadores das cidades. É preciso estimular suas habilidades e conhecimentos de modo a fazer com que suas futuras decisões interfiram positivamente no bem-estar social (Vilaça \& Araújo, 2016).

Algumas iniciativas destacam-se ao redor do mundo, envolvendo Fab Labs e ensino de crianças. Em 2007, foi criado o Fab Lab Kids, primeiro projeto que promove a aprendizagem de crianças e adolescentes por meio das tecnologias digitais, idealizado pelo Fab Lab Barcelona (Angelo et al., 2015). Angelo et al. (2015) ressalta que a partir desta iniciativa, os projetos envolvendo crianças e Fab Labs passaram a se difundir em diferentes países, com as mais diversas abordagens de aprendizagem. Em exemplo a isso, destaca-se a primeira edição do Fab Lab Kids Brasil, em 2011, coordenado pela Associação Fab Lab Brasil, em conjunto com os Fab Labs Costa Rica, Lima e São Paulo, por meio de oficinas de fabricação digital com enfoque em temáticas socioambientais (Angelo et al., 2012).

Outra importante iniciativa no âmbito internacional é o Fab Lat Kids, uma rede Latino-Americana de Laboratórios de fabricação digital, fundada em 2014. Com a participação de laboratórios de países como Argentina, Bolívia, Brasil, Colômbia, Costa Rica, Equador, Peru e México, promove a aprendizagem de crianças e adolescentes com a inserção de tecnologias digitais, tendo como objetivo repensar a educação do futuro (Angelo et al., 2015). No Fab Lat Kids, destaca-se o projeto Emosilla, que promove a aproximação das crianças às técnicas de fabricação digital mediante à construção de uma cadeira, na qual expressam suas emoções por meio de desenhos e cores (Angelo et al., 2015). Este projeto alcançou mais de 300 crianças na faixa etária de 4 a 10 anos, em 9 países, ganhando, em 2015, o primeiro lugar no Global Fab Lab Awards (Angelo et al., 2015). Em 2016, o Fab Lat Kids recebeu terceiro lugar no prêmio Chevron Stem Education Awards, pela promoção da multiculturalidade por meio de tecnologias (León, 2016).

Além do Emosilla, pode-se citar outros projetos do Fab Lat Kids, como: o Fab Lamp, que envolve crianças de 7 a 11 anos, na criação e fabricação de luminárias modulares, utilizando fabricação digital e automação; o DigiToys, com crianças de 4 a 10 anos, realizando modelagem e impressão 3D de personagens por elas idealizados; o Kid Pix, com crianças de 6 a 11 anos, promovendo a interação entre $\mathrm{o}$ analógico e o digital, desenvolvendo pincéis em 
formato de pixel para colorir seus desenhos; o Alebrije, com crianças de 4 a 8 anos e seus pais, promovendo a criação de personagens da cultura mexicana, materializados no corte a laser, o My Drawbot, envolvendo crianças de 8 a 14 anos, introduzindo a robótica e programação, com robôs cortados a laser; e o projeto Fab Rhino, com crianças de 6 a 14 anos, também com seus pais, que consiste na montagem de animais em grande escala, com peças facetadas no corte a laser (León, 2016). Além do Fab Lab Kids Brasil já citado, outra referência brasileira voltada ao ensino maker são as redes de aprendizagem Mão na Massa e o evento Fab Learn (Raabe et al., 2018).

Com experiências notáveis envolvendo crianças e fabricação digital, existe no Brasil com grande destaque, o Fab Lab Pronto 3D (Laboratório de Prototipagem e Novas Tecnologias Orientadas ao 3D), localizado em Florianópolis, contando com mais três polos no estado de Santa Catarina - Brasil, nas cidades de Chapecó, Lages e Criciúma. O Pronto $3 \mathrm{D}$, é um espaço que proporciona a prática do ensino, pesquisa e extensão, por meio da materialização da forma utilizando técnicas automatizadas. Atende os mais diversos cursos, entre os segmentos de Design, Arquitetura, Engenharias e demais áreas que envolvam criação, desenvolvimento e produção de modelos, protótipos, maquetes e produtos em diversas escalas. Em 2019, ganhou o segundo lugar mundial no Chevron STEM Education Award, com o projeto 'Fabricando tartarugas para entender Tartarugas', com foco na preservação destes animais, da aluna Clara Andrezzo, do curso de Design da Universidade Federal de Santa Catarina (UFSC), orientado pela professora Dra. Regiane Trevisan Pupo.

A experiência relatada neste artigo ocorreu em uma das sedes do Fab Lab acima mencionado, o Pronto 3D Chapecó, o qual não está credenciado junto a rede internacional Fab Lab. Criado em 2013, vêm desenvolvendo um trabalho significativo junto aos cursos de Arquitetura e Urbanismo e Design da Universidade a qual está vinculado. E a partir do ano de 2019, passou a incorporar atividades com crianças, voltadas ao ensino da fabricação digital. Deste modo, o presente estudo aborda tais atividades desenvolvidas, que possuem o objetivo de introduzir conceitos de fabricação e prototipagem digitais na educação de alunos de escolas públicas do município de Chapecó - Santa Catarina, relacionando-os ao ambiente construído, de modo a estimular o processo criativo e cognitivo destes estudantes.

\section{METODOLOGIA}

A metodologia utilizada é definida como qualitativa, possuindo natureza aplicada, objetivos exploratórios e explicativos e procedimento de pesquisa-ação. A abordagem qualitativa, de acordo com Silveira e Córdova (2009), é caracterizada pelo aprofundamento do tema, e não quantificação, além de maior aproximação com o objeto de estudo. A natureza aplicada da investigação relaciona-se à aplicação prática, por meio de oficinas, gerando novos conhecimentos que alcançam a solução do incômodo (Silveira \& Córdova, 2009). Com relação aos objetivos exploratórios e explicativos, o primeiro se caracteriza por maior imersão do problema, enquanto que o segundo, prevê a verificação das condicionantes que determinam ou contribuem no estudo, para então contribuição por meio dos resultados encontrados (Gil, 2017).
O procedimento de pesquisa-ação é definido por Thiollent (1988) como uma averiguação social, promovida por uma ação - neste caso a oficina - em que a participação dos pesquisadores e participantes é colaborativa para alcance dos resultados. Fonseca (2002) contribui ao definir que a pesquisa-ação possui atividades premeditadas pelo investigador, inserindo seu próprio conhecimento para com os participantes, além de princípios de comportamento participativo e relação próxima ao sujeito. De acordo com Tripp (2005), a pesquisa-ação é dividida em três fases, que podem ocorrer no campo da prática ou da investigação, são elas: Planejamento, Implementação e Avaliação. Como instrumentos de coleta de dados, esta pesquisa faz o uso da observação, registro fotográfico e diálogos informais com os participantes no decorrer da ação.

A ação relatada neste artigo ocorreu no laboratório de fabricação e prototipagem digitais, Pronto 3D Chapecó. O projeto intitula-se Pronto Kids Chapecó e oportuniza a prática de projetos sociais, aproximando alunos da rede pública infantil das tecnologias digitais e motivando-os ao engajamento sobre reflexões críticas em relação à sustentabilidade, tecnologia e inovação. A investigação ocorreu em duas etapas (Figura 1):

a) Levantamento de Dados: revisão da literatura acerca da temática estudada, focando nos temas fabricação e prototipagem digitais, concepção da arquitetura e do urbanismo, ensino para crianças e práticas conscientes no ambiente construído. A partir deste referencial, foi possível a compreensão e o aprofundamento a respeito dos principais fundamentos que regem cada temática.

b) Oficinas Pronto Kids Chapecó: oficinas realizadas no laboratório Pronto 3D Chapecó, localizado na Universidade Comunitária da Região de Chapecó UNOCHAPECÓ. O público-alvo são crianças que estão entre a $2^{\mathrm{a}}$ e $4^{\mathrm{a}}$ série do ensino fundamental, em escolas da rede pública, com faixa etária de 7 a 9 anos. O número inicial de vagas para cada oficina foi estipulado em 15 participantes, incluindo docentes, técnicos-administrativos e bolsistas da pesquisa.


pelos autores (2020).

O objetivo da realização destes encontros é a aplicação de um método prático, fazendo o público-alvo interagir diretamente com as tecnologias disponíveis no espaço. A partir da manufatura de objetos lúdicos, que estimulem a exploração e interação dos membros envolvidos, pretende-se instigar suas capacidades criativas e de 
imaginação. Conforme citado anteriormente, estes laboratórios possuem diversos maquinários que possibilitam a materialização da forma, tais como cortadora a laser, impressora $3 \mathrm{D}$ e maquinário $\mathrm{CNC}$ Router.

Com relação às limitações da aplicação das oficinas, há a falta de conhecimento de crianças sobre a temática, o curto intervalo de tempo (cada oficina pode ocorrer em um único turno - matutino ou vespertino) e o deslocamento das crianças até a universidade, com certo grau de risco e custo do transporte. Tais limitações foram decisivas no número de encontros proposto, sendo esta a primeira edição do Pronto Kids Chapecó. Foram planejadas uma oficina piloto, para aproximação com o público, e três outras edições, abordando assuntos como sustentabilidade, urbanização, paisagismo e tecnologia, sendo cada edição voltada para a produção em um dos maquinários. Porém, em decorrência da pandemia mundial do Coronavírus (COVID-19), foi possível realizar somente duas oficinas, ainda no ano de 2019, sendo uma a oficina piloto.

As propostas seguiram a linha do desenvolvimento de objetos e ações voltadas ao ambiente construído. $\mathrm{Na}$ oficina piloto, foram produzidos jogos lúdicos na cortadora a laser, e na oficina seguinte, o foco foi o uso do maquinário CNC Router, no qual foram desenvolvidas pequenas caixas para descarte consciente de pilhas e baterias.

Por se tratar de um experimento pedagógico, cada oficina buscou repassar, de forma prática e inclusiva, o funcionamento das tecnologias, de modo a verificar e experimentar este novo processo de ensino com crianças. Assim, foram divididas nas seguintes etapas: a) apresentação do laboratório e dos maquinários existentes no local (cortadora a laser, impressora 3D e CNC Router); b) explicação da atividade a ser realizada; e c) desenvolvimento.

\section{RESULTADOS E DISCUSSÕES}

A apresentação dos resultados e discussões, baseados na realização de duas oficinas, é dividida nestes dois momentos, sendo o primeiro a oficina piloto e o segundo a primeira edição do Pronto Kids Chapecó.

\section{OFICINA PILOTO}

Buscando observar a receptividade das crianças em relação a temática e às propostas, foi desenvolvida primeiramente, uma Oficina Piloto, no período vespertino, no mês de agosto de 2019. Foram recebidas cerca de 25 crianças, com a faixa etária entre 7 a 8 anos, estudantes do $3^{\circ}$ ano do Ensino Fundamental de uma escola municipal localizada na cidade de Chapecó/SC.

No primeiro momento da oficina, realizou-se breve apresentação sobre o funcionamento do laboratório, mostrando seu espaço físico, com a exibição dos maquinários (cortadora a laser, CNC Router e impressora 3D). Também foram apresentados os conceitos que permeiam as tecnologias de fabricação e prototipagem digitais e os materiais utilizados para a materialização. Com exceção da CNC Router, por questões de segurança, as demais máquinas estavam em funcionamento. No momento, a máquina a laser estava cortando algumas peças para as atividades que seriam realizadas na atividade, enquanto que a impressora 3D estava prototipando um objeto para uma disciplina do curso de Arquitetura e Urbanismo da Unochapecó. Muitos questionamentos foram levantados por parte das crianças ao observarem os instrumentos em funcionamento, gerando certo entusiasmo com 0 fato até então inexplorado (Figura 2). Alguns alunos relataram já conhecer este tipo de tecnologia, por meio da internet, porém nunca haviam tido contato físico com a experiência.
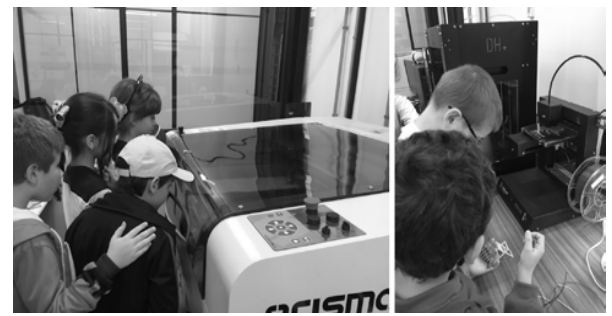

Figura 2: Conhecendo o espaço. Fonte: os autores (2019).

Após a explanação inicial, foram disponibilizados para as crianças dois modelos diferentes de atividades: um jogo sobre o sistema solar e um puzzle 3D de um esqueleto de dinossauro, sendo ambos para montagem. Os jogos foram elaborados e prototipados anteriormente à atividade, deixando somente algumas peças para manufatura no dia da oficina, pois, em conversa com os responsáveis pela escola municipal, os alunos poderiam permanecer menos de 1 hora no espaço, pois estavam agendadas outras visitações no campus da universidade.

Os jogos foram desenvolvidos em software CAD (Computer Aided Design - Desenho Assistido por Computador) e fabricados na cortadora a laser. Foram realizados um total de cinco exemplares de cada jogo. Desta forma, formaram-se grupos com cinco crianças, para que todos pudessem desenvolver a atividade de forma individual, pois cada um ganhou um exemplar de cada jogo. O primeiro jogo (Figura 3 ) tem a finalidade de mostrar aos estudantes a configuração espacial do Sistema Solar. Tem-se uma base onde ficam demarcados os planetas (Sol, Mercúrio, Vênus, Terra, Marte, Júpiter, Saturno, Urano e Netuno) de modo vazado, e separadamente tem-se o desenho de cada elemento. A criança deve preencher o vazio, de acordo com o desenho correto. A montagem realizada proporciona ao aluno o aprendizado de maneira lúdica.

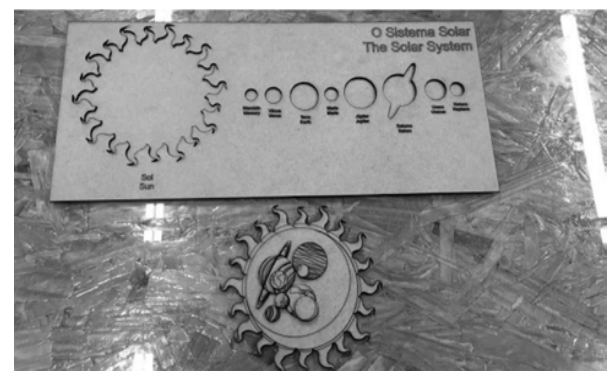

Figura 3: Jogo sobre o sistema solar. Fonte: os autores (2019).

$\mathrm{Na}$ Figura 4, as crianças estão montando o segundo modelo, o puzzle 3D do esqueleto de um dinossauro. Este jogo possui uma lógica de raciocínio e montagem mais complexa, pois é composto por um número maior de 

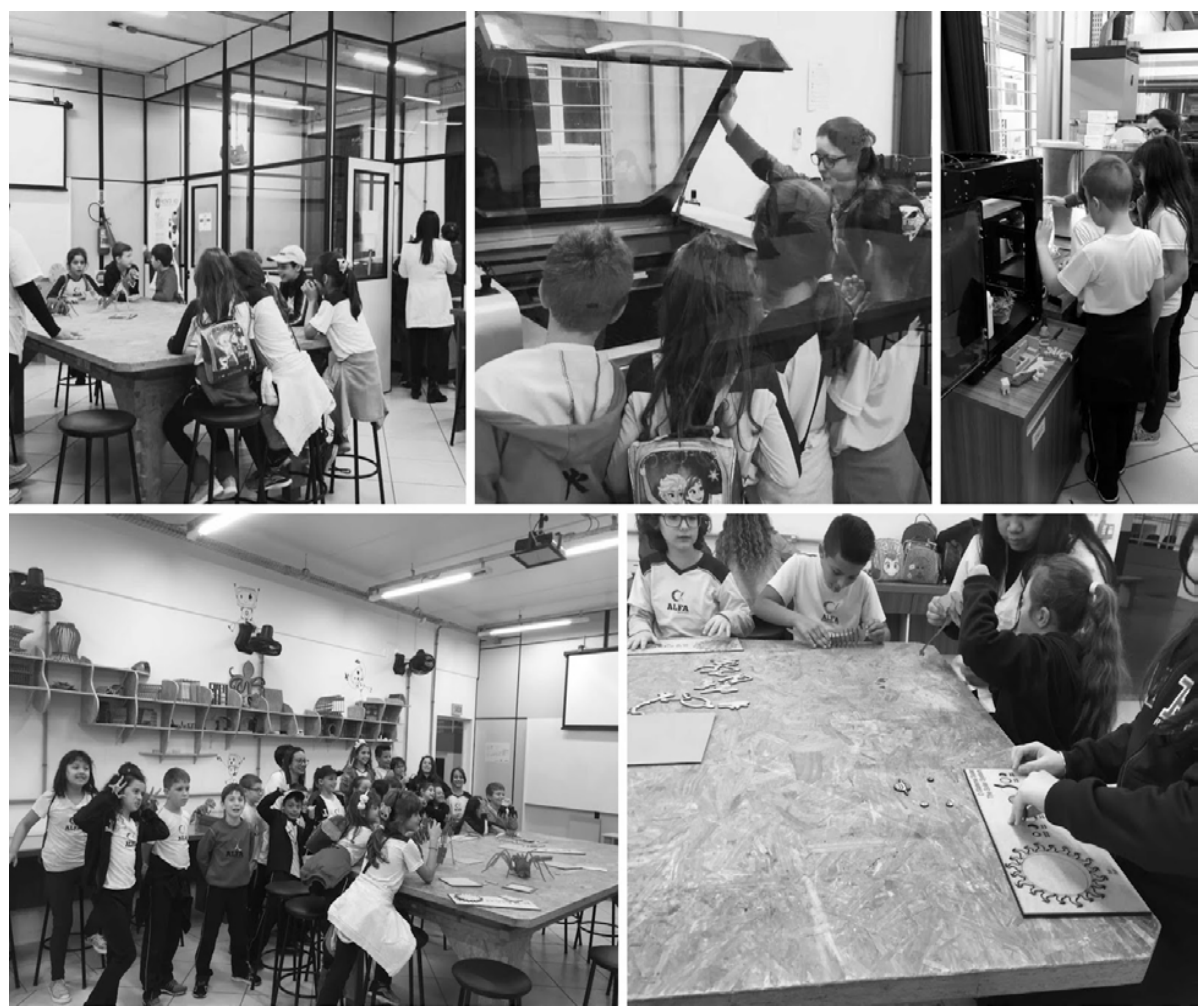

Figura 5: Realização Oficina Piloto. Fonte: os autores (2019).

peças, muitas delas de tamanho pequeno, que exigiram maior esforço e dedicação no processo.

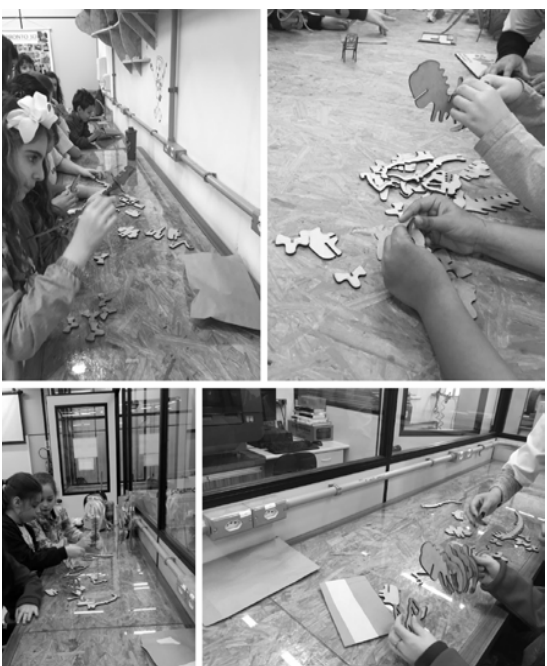

Figura 4: Montagem puzzle 3D. Fonte: os autores (2019).

Realizada a primeira oficina em formato piloto (Figura 5), pôde-se perceber que a temática "tecnologia" é satisfatoriamente compreendida pelas crianças, pois muitas já apresentam contato com smartphones e internet. Os alunos que não possuíam esta aproximação frequente, ou que não conheciam máquinas e processos de fabricação e prototipagem digitais, mostraram animação e interesse ainda maiores em relação às novidades, questionando diversas vezes e revelando-se envolvidos com a visita e as atividades propostas.

O processo, embora rápido, auxiliou na concepção de uma perspectiva inicial da interação das tecnologias com crianças, servindo de base para a planejamento das demais oficinas. Dados em relação a quantidade de alunos que o espaço comporta, nível de conhecimento e tempo previsto para realização das atividades foram coletados, com o propósito de suprir a demanda e expectativas dos participantes nas demais oficinas.

\section{PRONTO KIDS CHAPECÓ - PRIMEIRA EDIÇÃO}

A primeira edição do Pronto Kids Chapecó ocorreu em outubro de 2019, tendo como base as experiências promovidas pela oficina piloto. Inicialmente pensou-se em quais atividades seriam abordadas, considerando 0 escopo de todas as oficinas o ambiente construído.

Dessa forma, idealizou-se a criação de um objeto que as crianças pudessem levar para suas escolas e utilizar no dia a dia, mostrando a relação entre ambiente construído, tecnologia e sustentabilidade. A partir desse ponto, surgiu a ideia de fabricar caixas para o descarte consciente de pilhas e baterias (Figura 6). O protótipo foi modelado e planificado em software BIM. Assim como na oficina piloto, 
a fabricação foi realizada anteriormente, por conta do tempo disponível para o desenvolvimento da atividade. O corte ocorreu em maquinário CNC Router, com chapas de MDF (Medium-Density Fiberboard ou Placa de fibra de média densidade) de $9 \mathrm{~mm}$ de espessura. Em decorrência do processo de fabricação por meio de fresagem e por questões de segurança, todas as peças foram lixadas antes de serem distribuídas aos alunos, evitando acidentes.

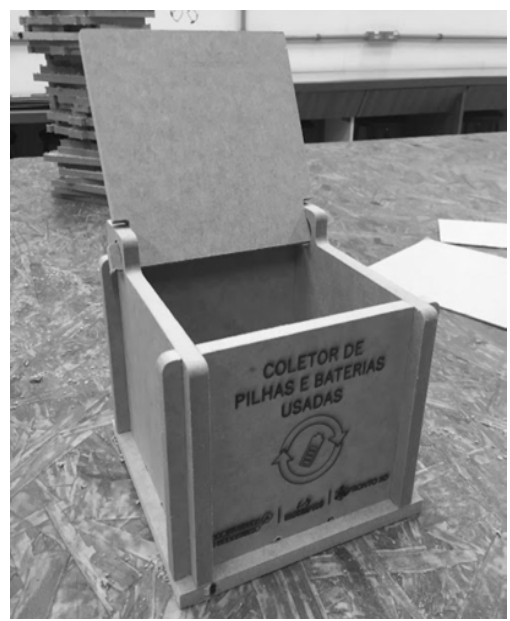

Figura 6: Caixa para descarte consciente de pilhas e baterias. Fonte: os autores (2019).

Nesta oficina foram atendidas 26 crianças, de 8 a 9 anos, estudantes do $4^{\circ}$ ano do Ensino Fundamental. Inicialmente havia sido definido o número de 15 participantes, contudo, devido ao custo com o transporte até a universidade, as escolas optaram por atender um número maior de alunos.

Inicialmente foi apresentado o laboratório e repassado aos estudantes os conceitos referentes às tecnologias de fabricação digital e prototipagem rápida, bem como materiais utilizados para a manufatura. Devido ao maior número de alunos, houve a separação da turma em dois grandes grupos para a realização de um tour pelo espaço, no qual foram mostrados os maquinários presentes no laboratório. Neste dia, todos os instrumentos puderam ser visualizados em funcionamento (Figura 7).

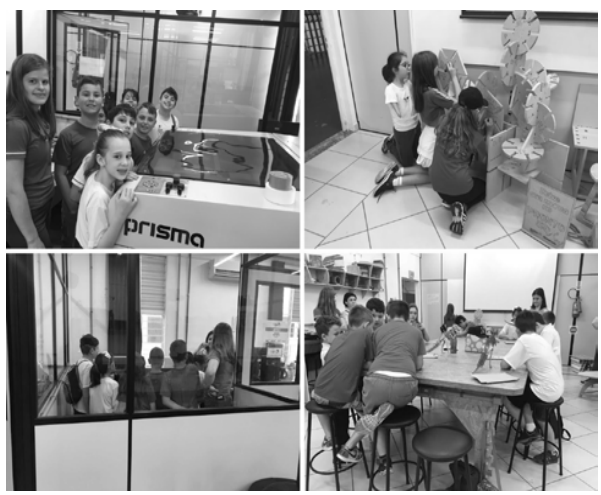

Figura 7: Familiarização com o espaço. Fonte: os autores (2019).
Durante a visita guiada, os alunos trouxeram vários questionamentos e demonstraram interesse às temáticas apresentadas. Conseguinte, foi proposto o desafio de montagem das caixas de descarte consciente (Figura 8). Para facilitar o manuseio, foram criados encaixes, que dispensam o uso de cola, pregos ou outro tipo de material para fixação. O projeto também possuía certo grau de dificuldade, pois algumas partes, como a tampa, precisavam ser encaixadas antes da finalização da montagem. Apesar disso, as crianças solucionaram os problemas de maneira bastante eficiente, concluindo com facilidade.

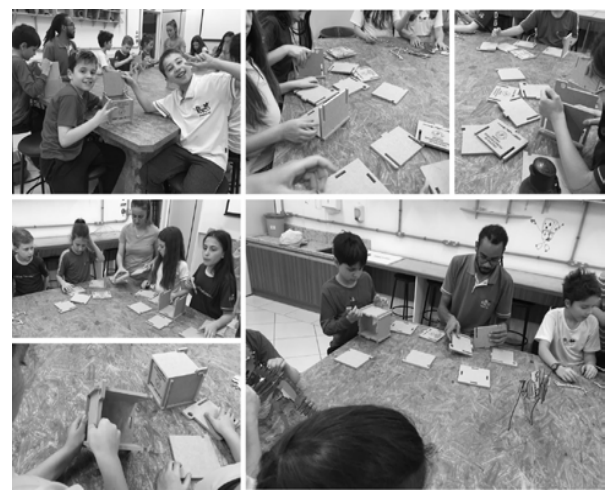

Figura 8: Desenvolvimento da oficina temática Pronto Kids

Chapecó - montagem de caixas para o descarte consciente de pilhas e baterias. Fonte: os autores (2019).

Ao fim da atividade (Figura 9), as caixas em MDF foram disponibilizadas para serem levadas pelas crianças até sua escola. Eles foram orientados a mantê-las em local visível, incentivando todo o público da escola a realizar o descarte consciente das pilhas e baterias. Além disso, foi proposto aos professores que os acompanhavam, a possibilidade de customização dos objetos por parte dos alunos, em um segundo momento.

Os resultados obtidos foram satisfatórios, pois as crianças se mostraram interessadas e engajadas em todas as propostas realizadas. Elas desempenharam de forma eficiente os encaixes no quebra-cabeça do sistema solar e do esqueleto do dinossauro, bem como a montagem das caixas para descarte correto de pilhas e baterias. Mostrouse um cenário surpreendente quanto ao entrosamento e domínio do conteúdo abordado, como também nos questionamentos realizados acerca do espaço físico e dos maquinários apresentados.

Para oficinas futuras, pretende-se aumentar o tempo de duração de cada atividade. Estuda-se propor exercícios nos quais as crianças possam modelar ou desenhar algo que desejam, com a possibilidade de fabricação durante a realização da atividade, estimulando assim o processo criativo e cognitivo do aluno, afastando-se do pressuposto de montar um objeto pronto.

\section{CONCLUSÃO}

As oficinas oportunizaram esclarecimento acerca das tecnologias digitais para as crianças, instigando-as a buscar um modo de produzir seus próprios objetos, refletindo na qualidade e sustentabilidade que podem promover ao ambiente construído. As atividades 

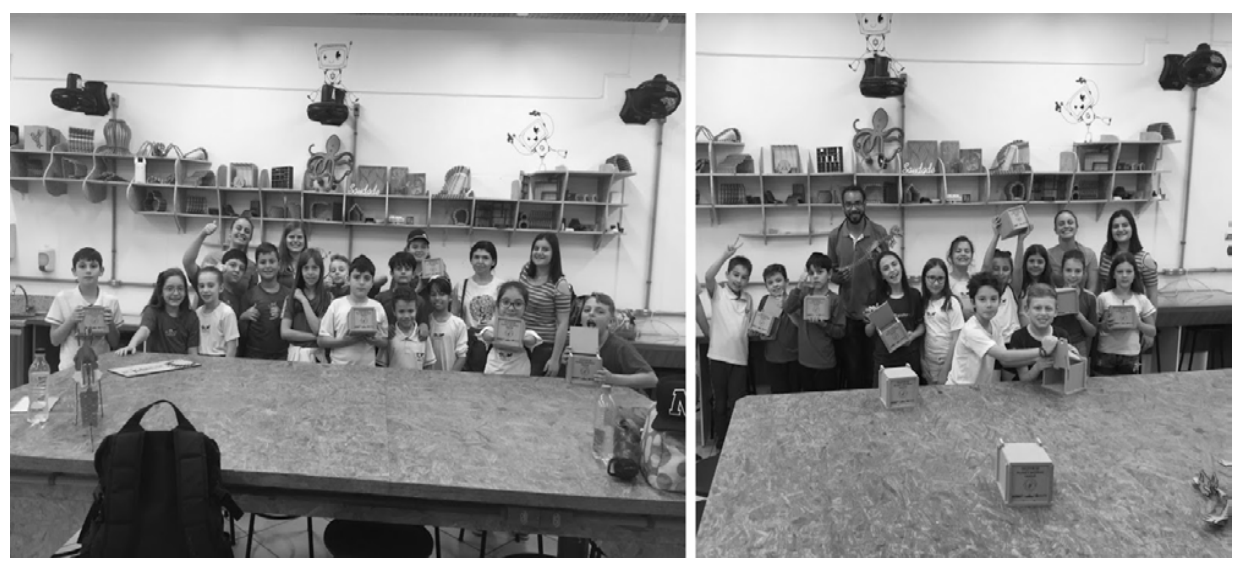

Figura 9: As duas turmas da primeira edição do Pronto Kids Chapecó. Fonte: os autores (2019).

desenvolvidas no Laboratório Pronto 3D Chapecó possuem um papel fundamental na compreensão e análise de como as ferramentas digitais têm interferido no processo criativo e cognitivo dos estudantes.

Ensinar conceitos de fabricação e prototipagem digitais para a educação infantil, principalmente crianças de escolas públicas, dando-lhes a oportunidade de percepção e interpretação de realidades diferentes, se mostrou satisfatório e de extrema relevância. Incentivar o uso de materiais sustentáveis e recicláveis, estimula a prática socioambiental, fazendo que a criança compreenda a atenção e cuidado que o meio ambiente necessita.

Como contribuição, percebeu-se a importância de se ensinar, ainda no início da formação, as variabilidades e usos que as tecnologias digitais podem proporcionar no processo de aprendizado. Evidencia-se a importância do contato de crianças com ferramentas digitais desde o momento em que passam a frequentar escolas, pois com o auxílio destas tecnologias, poderão transformar o espaço onde estão inseridas. Possibilitar às crianças esse contato reitera a necessidade de aproximar a universidade com a comunidade, pois é preciso estimular e incentivar o pensamento, para que práticas sociais sejam realizadas de modo eficaz e contínuo. A UNOCHAPECÒ, sede da realização da primeira edição do Pronto Kids Chapecó já aponta interesse em tornar a realização deste projeto contínua, pois percebe a receptividade da comunidade, associada à importância da prática.

Portanto, conclui-se que, quando o uso de ferramentas digitais é efetuado em prol do ensino infantil, o processo criativo e cognitivo das crianças é estimulado, de modo a motivá-las a colocar em prática aquilo que sonham e almejam. Essa sensação faz com que o aprender se torne descontraído, aguçando o sentimento de pertencimento ao local onde se relacionam.

\section{AGRADECIMENTOS}

A UNOCHAPECÓ pelo apoio financeiro e disponibilidade do espaço do laboratório para a execução deste projeto.

Ao Estado de Santa Catarina e ao Programa de Bolsas Universitárias de Santa Catarina (UNIEDU), pelo apoio financeiro firmado no projeto de pesquisa em questão.
A equipe do Laboratório Pronto 3D Chapecó, pela disponibilidade, organização e dedicação para que a realização das oficinas tivesse um ótimo êxito.

Às escolas municipais da cidade de Chapecó/SC que aceitaram o convite para a participação nas oficinas e engajando os alunos a querer conhecer e aprender mais sobre as tecnologias digitais.

\section{REFERÊNCIAS}

Angelo, A., Neves, H. M. D., \& Campos, P. E. F. d. (2012). Fab Lab Kids: Oficina de projetos socioambientais para crianças de escolas públicas fazendo uso da eletrônica e da fabricação digital. Paper presented at the SIGraDi Fortaleza, Brasil.

Angelo, A. G. S., Manna, I. L., Hernandez, O., Valdiviezo, M., Lastras, A. D. d. L., Salazar, O. I. C., . . . Zubieta, M. (2015). Fab Lab y Multiculturalidad en América Latina: El caso de Fab Lat Kids y el proyecto "Emosilla". Paper presented at the SIGraDi, São Paulo.

Ballerini, F. (2018). Fabricação Digital e Arquitetura: Para Além da Superespecialização dos Arquitetos em Direção à Colaboração. Pixo - Revista De Arquitetura, Cidade E Contemporaneidade, 2.

Brancher, V. R., Chenet, N., \& Oliveira, V. F. d. (2011). O lúdico na Aprendizagem Infantil. Revista do Centro de Educação, 27.

Fab Lab. (2020). Encontre um Fablab. Recuperado em 14 julho, 2020, de https://www.fablabs.io/.

Fonseca, J. J. S. (2002). Metodologia da pesquisa cientifica. Fortaleza: UEC

Gil, A. C. (2017). Como elaborar projetos de pesquisa. (Vol. 6 ). Rio de Janeiro: Atlas.

León, A. D. d. (2016). Dossiê Fab Lat Kids (pp. 3 ).

Papert, S. (1999). The Century's Greatest Minds. Time Magazine.

Pinto, S. L. U., Azevedo, I. S. C. d., Teixeira, C. S., Brasil, G. S. A. P. S., \& Hamad, A. F. (2018). O Movimento Maker: Enfoque nos Fab labs Brasileiros. Revista Livre de Sustentabilidade e Empreendedorismo, 3, 38-56.

Pupo, R. T. (2009). Inserção da prototipagem e fabricação digitais no processo de projeto : um novo desafio para o ensino de arquitetura. (doutorado). Universidade Estadual de Campinas, Campinas, SP.

Pupo, R. T., \& Celani, G. (2008). Implementando a fabricação digital e a prototipagem rápida em cursos de arquitetura: dificuldades e realidade. Paper presented at the SIGraDi, Cuba. 
Raabe, A., Metzger, J., Elieser Ademir de Jesus, Ivan Dias de Jesus Filho, \& Cucco, L. (2018). Movimento Maker e Construcionismo na Educação Básica: Fomentando o exercício responsável da liberdade. Workshop de Informática na Escola, 137-146.

Silva, C. S. G. d. (2019). Imersão nas tecnologias digitais para educação: uma experiência pedagógica no curso de Pedagogia da PUC-SP. (Mestrado). Pontifícia Universidade Católica de São Paulo, São Paulo.
Silveira, D. T., \& Córdova, F. P. (2009). UNIDADE 2 - A PESQUISA CIENTÍFICA. In E. d. UFRGS (Ed.), Métodos de pesquisa (pp. 31-42).

Thiollent, M. (1988). Metodologia da pesquisa-ação. São Paulo: Cortez \& Autores Associados.

Tripp, D. (2005). Pesquisa-ação: uma introdução metodológica. Educação e Pesquisa, 31, 443-466.

Vilaça, M. L. C., \& Araujo, E. V. F. d. (2016). Tecnologia, sociedade e educação na era digital. Duque de Caxias, RJ.: UNIGRANRIO. 